OPEN ACCESS

Edited by: Alessandro Antonelli, University of Pisa, Italy

Reviewed by: Salvatore Benvenga, University of Messina, Italy Tania M. Ortiga-Carvalho, Universidade Federal do Rio de Janeiro, Brazil

*Correspondence: Giulia Brigante giulia.brigante@gmail.com

Specialty section: This article was submitted to Thyroid Endocrinology,

a section of the journal

Frontiers in Endocrinology

Received: 02 September 2017

Accepted: 30 October 2017

Published: 14 November 2017

Citation:

Spaggiari G, Brigante G, De Vincentis S, Cattini U, Roli L, De Santis MC, Baraldi E, Tagliavini S,

Varani $M$, Trenti T, Rochira $V$,

Simoni M and Santi D (2017)

Probiotics Ingestion Does Not

Directly Affect Thyroid Hormonal

Parameters in Hypothyroid Patients

on Levothyroxine Treatment.

Front. Endocrinol. 8:316.

doi: 10.3389/fendo.2017.00316

\section{Probiotics Ingestion Does Not Directly Affect Thyroid Hormonal Parameters in Hypothyroid Patients on Levothyroxine Treatment}

\author{
Giorgia Spaggiari ${ }^{1,2}$, Giulia Brigante ${ }^{1,2 *}$, Sara De Vincentis ${ }^{1,2}$, Umberto Cattini $^{1}$, Laura Roli ${ }^{3}$, \\ Maria Cristina De Santis ${ }^{3}$, Enrica Baraldi ${ }^{3}$, Simonetta Tagliavini ${ }^{3}$, Manuela Varani ${ }^{3}$, \\ Tommaso Trenti ${ }^{3}$, Vincenzo Rochira ${ }^{1,2}$, Manuela Simoni ${ }^{1,2}$ and Daniele Santi ${ }^{1,2}$ \\ 1 Unit of Endocrinology, Department of Biomedical, Metabolic and Neural Sciences, University of Modena and Reggio Emilia, \\ Modena, Italy, ${ }^{2}$ Unit of Endocrinology, Department of Medicine, Endocrinology, Metabolism and Geriatrics, Azienda \\ Ospedaliero Universitaria di Modena, Modena, Italy, ${ }^{3}$ Department of Laboratory Medicine and Pathological Anatomy, \\ Azienda USL of Modena, Modena, Italy
}

Purpose: The relationship between probiotics and levothyroxine $\left(L T_{4}\right)$ requirement has not yet been investigated. The aim of this study was to assess whether a mixture of highly charged Lactobacilli and Bifidobacteria (VSL\#3 ${ }^{\circledR}$ ) is able to influence $\mathrm{LT}_{4}$ metabolism acting on the gut microbiota.

Methods: A prospective, randomized, single-blind, controlled, investigator-started clinical trial was carried out. Patients with primary hypothyroidism were randomly assigned to the study $\left(\mathrm{VSL} \# 3^{\circledR}+\mathrm{LT}_{4}\right)$ and the control group $\left(\mathrm{LT}_{4}\right)$. A 2-month treatment phase was followed by 2 months of follow-up. Clinical examination, blood tests for thyroid function and for peripheral tissue markers of thyroid hormones (PTM) were performed monthly. $\mathrm{LT}_{4}$ dose adjustments were performed when necessary.

Results: Thirty-nine patients were enrolled in the study group and 41 in the control group. No difference in thyroid function [thyroid-stimulating hormone (TSH), free triiodothyronine $\left(\mathrm{fT}_{3}\right)$, and free thyroxine $\left.\left(\mathrm{fT}_{4}\right)\right]$ and PTM was found between groups and among visits. $\mathrm{FT}_{3} / \mathrm{FT}_{4}$ ratio was directly correlated to $\mathrm{TSH}$ at each visit in both groups, with the exception of the first evaluation of probiotics-treated subjects (rho $=0.287, p=0.076$ ). $\mathrm{LT}_{4}$ daily dose adjustments occurred more frequently in the control than in the study group ( $p=0.007$ ), despite no differences in the mean $L T_{4}$ daily dose. In particular, $L T_{4}$ doses were increased six times in the control group and decreased four times in the study group.

Conclusion: VSL\#3 $3^{\circledR}$ does not directly alter thyroid functional compensation. A probioticsmediated influence on thyroid hormones homeostasis is suggested since probiotics supplementation could be able to prevent serum hormonal fluctuations.

ClinicalTrials.gov ID: Registration number NCT03095963.

Keywords: levothyroxine, probiotics, VSL\#3 ${ }^{\oplus}$, thyroid-stimulating hormone, thyroid hormones, gut microbiota 


\section{INTRODUCTION}

Levothyroxine $\left(\mathrm{LT}_{4}\right)$ is the standard therapeutic choice in hypothyroidism replacement therapy (1). Representing the synthetic equivalent of native tetraiodothyronine $\left(\mathrm{T}_{4}\right), \mathrm{LT}_{4}$ modulates the same biological functions (2). In the literature, several peripheral markers have been proposed to measure the peripheral response to thyroid hormones (THs), such as lipid profile [total cholesterol $(\mathrm{CH})$, low density lipoprotein $\mathrm{CH}$, and lipoprotein(a)], coagulation parameters (plasminogen activator inhibitor), hepatic protein synthesis indexes [sex hormone-binding globulin (SHBG) and ferritin], muscular system (creatine phosphokinase and myoglobin), bone metabolism parameters (osteocalcin and urinary N-telopeptide), and selected enzymatic activity [angiotensin-converting enzyme (ACE) and glucose-6-phosphate dehydrogenase] (2).

$\mathrm{LT}_{4}$ is administered orally, dissolved by gastric acids and absorbed mainly in jejunum and ileum (1). Many factors influence $\mathrm{LT}_{4}$ absorption, such as food and beverages (3-5), drugs (6-13), and pathological conditions impairing the digestive tract absorptive ability $(7,14,15)$. Moreover, several drugs are able to interfere with $\mathrm{TH}$ requirements increasing $\mathrm{LT}_{4}$ metabolism and clearance (4), or acting on expression and activity of catabolic enzymes (16).

The $\mathrm{LT}_{4}$ activation and inactivation occur through the action of deiodinases (17). Reversible sulfotransferases and glucuronyltransferases mediate the inactivation of $\mathrm{TH}$ in the liver, increasing iodothyronines water-solubility, promoting biliary and urinary clearance (17). In the bowel, gut bacteria expressing $\beta$-glucuronidases and sulfatase enzymes are able to hydrolyze glucuronidated and sulfated iodothyronines metabolites $(17,18)$. In this way, lipophilic deconjugated iodothyronines can be reabsorbed, constituting the enterohepatic recycle of THs $(17,18)$. According to this mechanism, $\mathrm{LT}_{4}$ requirement could be regulated acting on intestinal bacteria and modifying THs enterohepatic recycle. In this context, gut can be considered a possible reservoir of THs (17), although a clear in vivo demonstration is still lacking.

Probiotics are defined as live microorganisms which, when consumed in adequate amounts, confer a health effect on the host (19). They are not considered drugs by the current international legislation (19). Probiotics limit the intestinal colonization from pathogenic bacteria $(20,21)$, improve the physiological bowel barrier function $(20,21)$, and influence the pro-inflammatory and anti-inflammatory cytokines production (20-23). However, the mechanism by which probiotics contribute to microbiota modulation has not been completely clarified so far (20). Although an effect of probiotics on health has been proposed in several pathologic conditions $(18,20,24-37)$, a clear demonstration is still lacking.

Up to now, there is low evidence of probiotics interaction with concomitant drug ingestion, considering their influence on bacteria enzymatic activity $(38,39)$. Since products containing probiotics are very popular, it would be important to discover any possible interference with pharmacological therapies. This interaction could result in clinical consequences on $\mathrm{LT}_{4}$-treated patients simultaneously taking probiotics. This is the first clinical trial designed to investigate whether a mixture of highly charged Lactobacilli and Bifidobacteria (VSL $\# 3^{\circledR}$ ) is able to influence $\mathrm{LT}_{4}$ metabolism acting on the gut microbiota in hypothyroid patients.

\section{MATERIALS AND METHODS}

A prospective, randomized, single-blind, controlled, investigatorstarted clinical trial was carried out (ClinicalTrials.gov ID: registration number NCT03095963).

Patients' inclusion criteria were: primary hypothyroidism on $\mathrm{LT}_{4}$ replacement therapy, thyroid-stimulating hormone (TSH), $\mathrm{fT}_{3}$ and $\mathrm{fT}_{4}$ in the normal range, stable $\mathrm{LT}_{4}$ dosage during the 6 months before enrolment, Caucasian ethnicity, age 18-65 years. Exclusion criteria were total thyroidectomy for thyroid carcinoma, intestinal malabsorption (e.g., bariatric surgery, inflammatory bowel diseases, celiac disease), ongoing therapies interfering with $\mathrm{LT}_{4}$ absorption and/or metabolism (i.e., aluminum-containing antacids, sucralfate, proton pump inhibitors, calcium carbonate, raloxifene, bile acids sequestrants, and ferrous sulfate), and antibiotics treatment in the 6 months before enrolment.

\section{Study Design}

Consecutive patients on $\mathrm{LT}_{4}$ replacement therapy attending the Endocrinology Unit of Modena (Italy) were screened. According to inclusion and exclusion criteria, 80 participants were enrolled and randomized in study or control group. The random allocation sequence was generated using "Statistical Package for the Social Sciences" software for Macintosh (SPSS) considering a 1:1 ratio by the statistician of the Unit. Clinicians evaluating and enrolling patients were blinded to the randomization list. The study design provided a monthly visit for a 4 months overall time-frame. Patients assigned to the study group took the probiotic supplement VSL\# $3^{\circledR}$ for 2 months, followed by a 2-month period of follow-up (Figure 1). All patients were instructed to take $\mathrm{LT}_{4}$ tablets with water in the morning with empty stomach, at least $30 \mathrm{~min}$ before breakfast and/or other medicine ingestion. Study group patients were taught to assume the probiotic supplement at least $2 \mathrm{~h}$ after $\mathrm{LT}_{4}$ administration, irrespective of meals, to dissolve it in a cold beverage and to store it in a refrigerator $\left(2-8^{\circ} \mathrm{C}\right)$, in order to preserve bacteria load. Patients assigned to the control group continued their $\mathrm{LT}_{4}$ therapy without placebo administration.

The study design was single-blind since only the clinician was aware of the allocation. The VSL $\# 3^{\circledR}$ administration was provided by nurses. Participants were invited to return all used and unused sachets to count the number of opened sachets per the number of treatment days.

All patients underwent five monthly visits (baseline, visit 1 , 2,3 , and 4), in which anthropometrical evaluation (weight and height) and hormonal function assessment were performed. A fasting blood sample was taken in the morning at each visit before $\mathrm{LT}_{4}$ ingestion. Since TSH results were available the same day of blood sampling, $\mathrm{LT}_{4}$ daily dose was promptly adjusted on occurrence of TSH alterations (laboratory reference range: $0.35-4.94 \mu \mathrm{IU} / \mathrm{mL}$ ), according to clinical guidelines (40). 


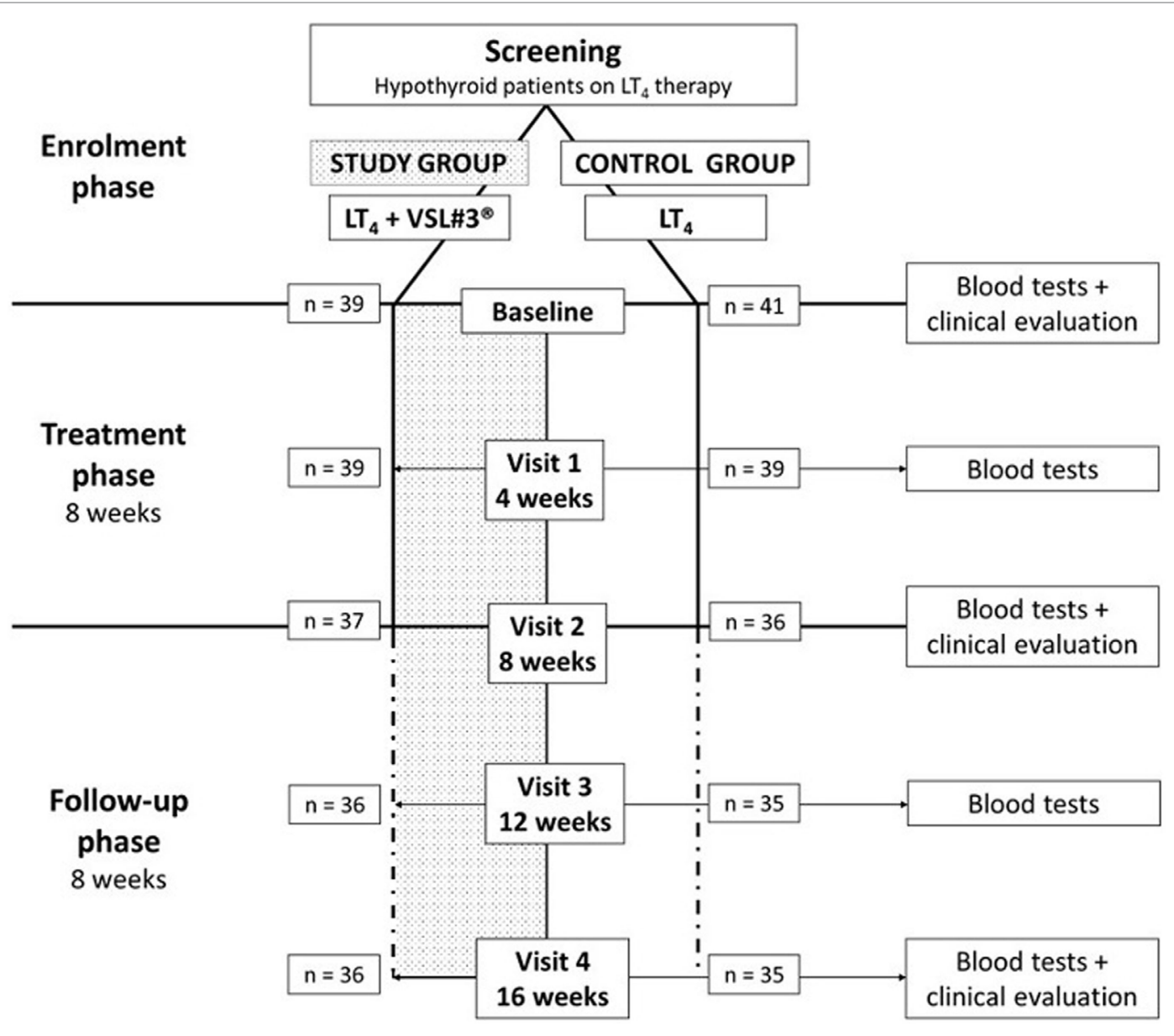

FIGURE 1 | Study design.

At baseline, visit 2, and visit 4, patients underwent clinical examination with heart rate and blood pressure evaluation (Figure 1). During each visit, the following data were collected: probiotic ingestion, sex, age, hypothyroidism etiology, $\mathrm{LT}_{4}$ formulation dose and brand, body mass index (BMI), body surface area (BSA), systolic blood pressure, diastolic blood pressure, heart rate, TSH, $\mathrm{fT}_{4}, \mathrm{fT}_{3}$, and any possible $\mathrm{LT}_{4}$ posology adjustment.

\section{VSL\#3 ${ }^{\circledR}$}

VSL $\# 3^{\circledR}$ is a multistrain probiotic supplement available in packets. Each VSL $\# 3^{\circledR}$ sachet contains a high concentration $\left(450 \times 10^{9} \mathrm{CFU}\right)$ of live freeze-dried bacteria, belonging to eight different strains, i.e., Bifidobacterium breve, Bifidobacterium longum, Bifidobacterium infantis, Lactobacillus acidophilus, Lactobacillus plantarum, Lactobacillus paracasei, Lactobacillus bulgaricus, and Streptococcus thermophilus. The compound was chosen considering its highest concentration among commonly used probiotics-containing products.

\section{Laboratory Analyses}

During the 4 months evaluation timeline, thyroid function assessment ( $\mathrm{TSH}, \mathrm{fT}_{3}, \mathrm{fT}_{4}$ ) was performed monthly to revise $\mathrm{LT}_{4}$ dosage if necessary. Blood samples for each patient at each visit were stored at $-20^{\circ} \mathrm{C}^{\circ}$ until the end of enrolment, to measure peripheral tissue markers of THs. Table S1 in Supplementary Material summarizes methodologies used for each assay and the respective intra- and inter-assay coefficient of variation.

\section{Statistical Analysis}

Considering that no studies so far evaluated the influence of probiotics on hormonal measurements, the sample size was calculated using a previous study aiming at analyzing the influence on $\mathrm{LT}_{4}$ absorption. Singh et al. found a TSH decrease of about $70 \%$ after concomitant ingestion of calcium and $\mathrm{LT}_{4}$ in patients treated for hypothyroidism (41). Thus, assuming a similar variation of TSH in patients treated with both probiotics and $\mathrm{LT}_{4}$, using ANOVA univariate statistical analysis, considering a statistical power of $90 \%$ and an $\alpha$-error of 0.05 , the required sample size was of 80 patients. Setting a 1:1 case-control ratio, the final sample size was of 40 patients for each group.

Continuous parameters were compared between study and control groups through ANOVA univariate and/or MannWhitney test, according to data distribution, evaluated by Kolmogorov-Smirnov test. Categorical variables were compared 
with Chi-square or Fisher exact test. The changes after treatment were evaluated considering repeated variables, using Wilcoxon signed-rank test. The degree of correlation between ordinal variables was studied using Spearman rho correlation test.

In order to evaluate THs metabolism and pituitary feedback, $\mathrm{fT}_{3} / \mathrm{fT}_{4}, \mathrm{fT}_{3} / \mathrm{TSH}$, and $\mathrm{fT}_{4} / \mathrm{TSH}$ ratios were calculated. Moreover, hormonal measurements were adjusted for the anthropometrical available variables (BMI and BSA).

Statistical analysis was performed using the "Statistical Package for the Social Sciences" software for Macintosh (version 21.0; SPSS Inc., Chicago, IL, USA). Statistical significance was considered significant when $p<0.05$.

\section{Ethical Approval}

The Institutional Review Board of Modena (Comitato Etico di Modena) approved the study (code 184/13, approved on 12th November 2013).

All procedures performed in studies involving human participants were in accordance with the ethical standards of the institutional and/or national research committee and with the 1964 Helsinki declaration and its later amendments or comparable ethical standards.

\section{Informed Consent}

Written informed consent was obtained from all individual participants included in the study.

\section{RESULTS}

One hundred and twenty hypothyroid patients on $\mathrm{LT}_{4}$ replacement therapy were screened and 80 patients were enrolled according to inclusion and exclusion criteria (Figure 2). Thirtynine patients (48.8\%) entered the study group and $41(51.2 \%)$ the control group. Baseline characteristics of patients are shown in Table 1.

At baseline, three male patients (3.75\%) entered the study group while no male patients entered the control group. This gender disparity is in line with the known highest female incidence of primary hypothyroidism (1). Three patients (one male

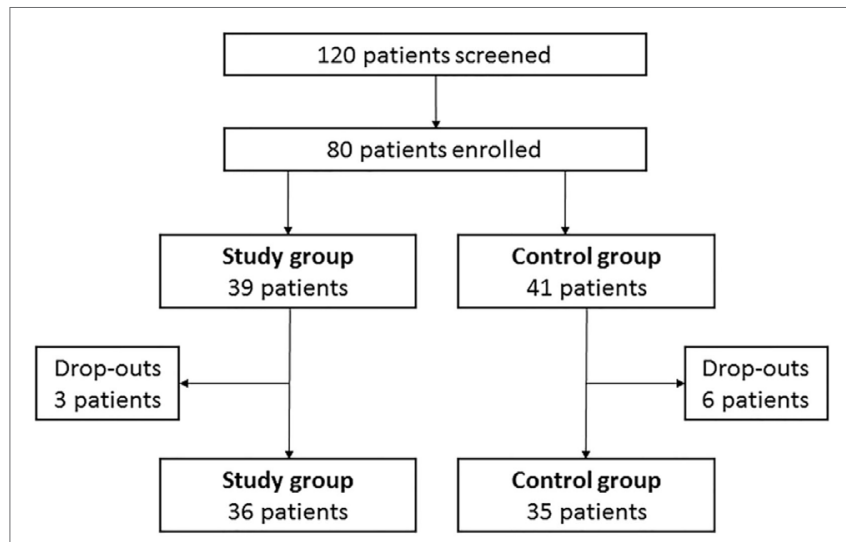

FIGURE 2 | Flow chart of the study. and two females) $(7.69 \%)$ dropped out from the study group and six female patients (14.63\%) dropped out from the control group (Figure 2). No adverse events were recorded in both groups and dropouts occurred for patients' decision.

No differences were observed between study and control group, considering anthropometrical variables (Table 1). Only heart rate was significantly higher in the control than in the study group $(p=0.043)$.

The main cause of hypothyroidism was Hashimoto thyroiditis, occurring with similar incidence both in study and control group (71.8 and $73.2 \%$, respectively; $p=0.916)$. Only two patients $(4.88 \%)$ in the control group presented an iatrogenic hypothyroidism, due to total thyroidectomy or to radioiodine treatment. The majority of the patients was treated with branded $\mathrm{LT}_{4}$ (97.5\% in both groups; $p=0.971$ ) and only the tablet formulation was used. Among branded $\mathrm{LT}_{4}$, Eutirox ${ }^{\circledR}$ was the mostly taken $(94.9 \%$ in the study vs. $90.2 \%$ in the control group; $p=0.432)$. The remaining patients were treated with Tirosint ${ }^{\circledR}(2.6 \%$ in the study group vs. $7.3 \%$ in the control group; $p=0.644)$.

The calculated compliance for probiotics ingestion was $79.2 \%$ in the study group.

\section{Thyroid Hormones}

Thyroid-stimulating hormone, $\mathrm{fT}_{3}, \mathrm{fT}_{4}$ did not change between study and control group at each visit, as well as among visits in the two groups (Table 2). The lack of significance was confirmed after adjustment for BMI and BSA or considering hormonal ratios (f $\mathrm{f}_{3} / \mathrm{fT}_{4}, \mathrm{fT}_{3} / \mathrm{TSH}$, and $\mathrm{fT}_{4} / \mathrm{TSH}$ ).

In the control group, TSH was inversely related to $\mathrm{fT}_{4}$ and $\mathrm{fT}_{3}$ (rho $=-0.593, p<0.001$ and rho $=-0.293, p=0.004$, respectively) while $\mathrm{fT}_{4}$ and $\mathrm{fT}_{3}$ were directly related each other (rho $=0.269, p=0.004$ ), as expected according to TH physiology. Unexpectedly, the correlation between TSH and $\mathrm{fT}_{3}$ was lost after adjustment for age $(p=0.377)$ and BMI $(p=0.286)$. Similarly, TSH was inversely related to $\mathrm{fT}_{4}(\mathrm{rho}=-0.547, p<0.001)$ in the study group, but their correlation to $\mathrm{fT}_{3}$ was absent $(p=0.516$ and $p=0.462$, respectively). However, in both groups, the correlation was lost when each visit was considered separately, suggesting that the low number of cases evaluated in subgroup analyses impaired the statistical power.

Regarding anthropometrical features at baseline, TSH was directly related to BMI (rho $=0.227, p=0.047)$, but not to BSA (rho $=0.167, p=0.146$ ). Accordingly, $\mathrm{fT}_{4}$ was inversely related to BMI (rho $=-0.260, p=0.023$ ), while $\mathrm{fT}_{3}$ did not correlate with any anthropometrical variable. Moreover, a direct correlation between TSH serum levels and systolic and diastolic pressures was found ( $\mathrm{rho}=0.282, p=0.012$ and $\mathrm{rho}=0.227$, $p=0.046$, respectively). On the contrary, neither $\mathrm{fT}_{4}$ nor $\mathrm{fT}_{3}$ correlated with blood pressure. Similarly to what obtained for hormonal data, these relationships were lost considering following visits. Moreover, heart rate did not correlate to THs at any time point.

Evaluating the peripheral conversion of $\mathrm{TH}$, the $\mathrm{fT}_{3} / \mathrm{fT}_{4}$ ratio was directly related to TSH at each visit in the control group, as expected for the known feedback mechanism. In the study group, this correlation was lost at visit 1 (rho $=0.287, p=0.076)$, after 
TABLE 1 | Patients data and characteristics collected at baseline.

\begin{tabular}{|c|c|c|c|c|}
\hline & Reference range & Study group & Control group & $p$ Value \\
\hline Patients number & - & 39 & 41 & - \\
\hline Female, $n(\%)$ & - & $36(92.3)$ & $41(100)$ & 0.222 \\
\hline Male, $n(\%)$ & - & $3(7.7)$ & $0(0)$ & 0.222 \\
\hline Autoimmune thyroiditis, $n(\%)$ & - & $28(71.8)$ & $30(73.2)$ & 0.9160 \\
\hline Non-autoimmune hypothyroidism, $n$ (\%) & - & $11(28.2)$ & $9(22)$ & 0.698 \\
\hline Post-thyroidectomy, $n$ (\%) & - & $0(0)$ & $1(2.4)$ & 0.960 \\
\hline Post radioiodine, $n(\%)$ & - & $0(0)$ & $1(2.4)$ & 0.960 \\
\hline Eutirox $^{\circledast}, n(\%)$ & - & 37 (94.9) & $37(90.2)$ & 0.718 \\
\hline Tirosint $^{\circledR}, n(\%)$ & - & $1(2.6)$ & $3(7.3)$ & 0.644 \\
\hline Non-branded $\mathrm{LT}_{4}, n(\%)$ & - & $1(2.6)$ & $1(2.4)$ & 0.496 \\
\hline Age (years) & - & $49.6 \pm 10.39$ & $49.33 \pm 11.38$ & 0.791 \\
\hline $\mathrm{BMl}\left(\mathrm{kg} / \mathrm{m}^{2}\right)$ & $18.50-24.99$ & $27.77 \pm 6.14$ & $27.71 \pm 6.12$ & 0.735 \\
\hline SBP (mmHg) & $90-120$ & $116 \pm 14$ & $115 \pm 15$ & 0.703 \\
\hline $\mathrm{DBP}(\mathrm{mmHg})$ & $60-80$ & $74 \pm 8$ & $73 \pm 10$ & 0.809 \\
\hline Heart rate (bpm) & $60-100$ & $70 \pm 6$ & $72 \pm 7$ & 0.043 \\
\hline $\mathrm{TSH}(\mu \mathrm{lU} / \mathrm{mL})$ & $0.35-4.94$ & $2.37 \pm 1.66$ & $2.72 \pm 1.83$ & 0.308 \\
\hline $\mathrm{fT}_{3}(\mathrm{pg} / \mathrm{mL})$ & $1.7-3.7$ & $2.7 \pm 0.3$ & $2.6 \pm 0.3$ & 0.871 \\
\hline $\mathrm{fT}_{4}(\mathrm{pg} / \mathrm{mL})$ & $7-15$ & $10.8 \pm 1.6$ & $10.9 \pm 1.6$ & 0.749 \\
\hline $\mathrm{LT}_{4}$ dose $(\mu \mathrm{g} /$ day $)$ & - & $78.21 \pm 26.95$ & $74.56 \pm 23.02$ & 0.789 \\
\hline $\mathrm{LT}_{4}$ dose $(\mu \mathrm{g} / \mathrm{kg} /$ day $)$ & - & $1.06 \pm 0.38$ & $1.08 \pm 0.39$ & 0.855 \\
\hline
\end{tabular}

Data are expressed as mean $\pm S D$. $p$ value is considered significant when $<0.05$.

$B M I$, body mass index; bpm, beats per minute; $D B P$, diastolic blood pressure; $f T_{3}$, free triiodothyronine; $f T_{4}$, free tetraiodothyronine; $L T_{4}$, levothyroxine; $S B P$, systolic blood pressure; TSH, thyroid-stimulating hormone.

TABLE 2 | Thyroid axis hormonal measurements.

\begin{tabular}{|c|c|c|c|c|}
\hline & $\begin{array}{c}\text { Reference } \\
\text { range }\end{array}$ & Study group & $\begin{array}{l}\text { Control } \\
\text { group }\end{array}$ & $p$ Value \\
\hline $\mathrm{TSH}(\mu \mathrm{IU} / \mathrm{mL})$ & $0.35-4.94$ & & & \\
\hline Baseline & & $2.37 \pm 1.66$ & $2.81 \pm 1.88$ & 0.308 \\
\hline Visit 1 (treatment phase) & & $2.35 \pm 1.68$ & $2.97 \pm 3.38$ & 0.565 \\
\hline Visit 2 (treatment phase) & & $2.17 \pm 1.84$ & $3.88 \pm 7.57$ & 0.344 \\
\hline Visit 3 (follow-up phase) & & $2.53 \pm 3.08$ & $2.84 \pm 2.47$ & 0.343 \\
\hline Visit 4 (follow-up phase) & & $2.23 \pm 1.72$ & $3.27 \pm 4.24$ & 0.344 \\
\hline$p$ value & - & 0.896 & 0.970 & - \\
\hline $\mathrm{fT}_{3}(\mathrm{pg} / \mathrm{mL})$ & $1.7-3.7$ & & & \\
\hline Baseline & & $2.7 \pm 0.3$ & $2.6 \pm 0.3$ & 0.871 \\
\hline Visit 1 (treatment phase) & & $2.7 \pm 0.4$ & $2.7 \pm 0.3$ & 0.894 \\
\hline Visit 2 (treatment phase) & & $2.7 \pm 0.4$ & $2.7 \pm 0.3$ & 0.759 \\
\hline Visit 3 (follow-up phase) & & $2.6 \pm 0.4$ & $2.7 \pm 0.3$ & 0.079 \\
\hline Visit 4 (follow-up phase) & & $2.7 \pm 0.4$ & $2.7 \pm 0.3$ & 0.809 \\
\hline$p$ value & - & 0.873 & 0.592 & - \\
\hline $\mathrm{fT}_{4}(\mathrm{pg} / \mathrm{mL})$ & $7-15$ & & & \\
\hline Baseline & & $10.8 \pm 1.6$ & $10.9 \pm 1.6$ & 0.902 \\
\hline Visit 1 (treatment phase) & & $10.9 \pm 1.3$ & $11.0 \pm 1.6$ & 0.850 \\
\hline Visit 2 (treatment phase) & & $10.9 \pm 1.3$ & $10.9 \pm 1.6$ & 0.962 \\
\hline Visit 3 (follow-up phase) & & $10.7 \pm 1.2$ & $10.9 \pm 1.6$ & 0.820 \\
\hline Visit 4 (follow-up phase) & & $10.9 \pm 1.6$ & $10.7 \pm 1.7$ & 0.424 \\
\hline$p$ value & - & 0.968 & 0.805 & - \\
\hline
\end{tabular}

Data are expressed as mean $\pm S D$. $p$ value is considered significant when $<0.05$.

$\mathrm{fT}_{3}$, free triiodothyronine; $\mathrm{fT}_{4}$, free tetraiodothyronine; $T S H$, thyroid-stimulating hormone.

one month of probiotics treatment, suggesting a possible probiotics effect on this central pathway.

\section{$\mathbf{L T}_{4}$ Dose Adjustments}

$\mathrm{LT}_{4}$ therapy was adjusted 10 times in 8 patients $(10 \%$ of the total number of patients). In particular, $\mathrm{LT}_{4}$ doses were increased six times in four patients (the same patient needed three dosage adjustments) in the control group and decreased four times in
TABLE 3 | Distribution of $L T_{4}$ dose adjustments among groups.

\begin{tabular}{lccr}
\hline & $\begin{array}{c}\mathbf{L T}_{4} \text { dose } \\
\text { decrease }\end{array}$ & $\begin{array}{l}\mathbf{L T}_{4} \text { dose } \\
\text { increase }\end{array}$ & Total \\
\hline $\begin{array}{l}\text { All patients } \\
\text { Number of patients }\end{array}$ & 4 & 4 & 8 \\
Times of $L T_{4}$ dose adjustments & 4 & 6 & 10 \\
Study group & & & 4 \\
Number of patients & 4 & 0 & 4 \\
Times of $L T_{4}$ dose adjustments & 4 & & 4 \\
Control group & & 4 & 6 \\
Number of patients & 0 & 6 & 4 \\
Times of $L T_{4}$ dose adjustments & 0 & & \\
\hline
\end{tabular}

$L T_{4}$, levothyroxine.

four different patients in the study group (Table 3). Dose adjustments were performed upon occurrence of alterations of serum TSH levels, as suggested by clinical guidelines (40). Interestingly, $\mathrm{LT}_{4}$ dose adjustments occurred more frequently in the control than in the study group $(p=0.007)$. However, the mean $\mathrm{LT}_{4}$ daily dose did not differ between groups $(p=0.419)$ and among visits ( $p=0.916$ in the control group and $p=0.970$ in the study group). Considering patients with unchanged $\mathrm{LT}_{4}$ dose during the trial (90\% of the total number of patients), the lack of hormonal changes after probiotic treatment remained.

As expected, $\mathrm{LT}_{4}$ dose was directly related to $\mathrm{fT}_{4}$ in the study (rho $=0.299, p=0.001$ ) and control group (rho $=0.457$, $p<0.001$ ), respectively. Moreover, $\mathrm{LT}_{4}$ dose was inversely related to TSH in the study (rho $=-0.448, p<0.001$ ) and control group (rho $=-0.205, p=0.029$ ), respectively. Considering each visit separately these relationships remained. However, $\mathrm{LT}_{4}$ dose was not correlated with serum $\mathrm{fT}_{3}$ levels in any group (study group: rho $=-0.041, p=0.579$; control group: $r h o=-0.079, p=0.289$ ). 


\section{Peripheral Tissue Markers}

All the peripheral tissue markers of THs evaluated did not change between groups or among visits (Table 4).

Considering baseline, TSH was directly related to $\mathrm{CH}$ (rho 0.278 , $p<0.001)$, CK (rho $=0.143, p=0.007)$, myoglobin $($ rho $=0.134$, $p=0.010$ ), and ferritin (rho $=0.187, p<0.001$ ) and inversely to SHBG (rho $=-0.160, p=0.002$ ). $\mathrm{FT}_{4}$ was inversely related to $\mathrm{CH}(\mathrm{rho}=-0.247, p<0.001)$ and myoglobin $(\mathrm{rho}=-0.112$, $p=0.033)$ and directly to SHBG (rho $=0.211, p<0.001)$. $\mathrm{FT}_{3}$ was inversely related to lipoprotein(a) (rho $=-0.185, p<0.001)$ and osteocalcin ( $\mathrm{rho}=-0.105, p=0.045$ ). At visit 2 , TSH remained directly related to $\mathrm{CH}(\mathrm{rho}=0.389, p=0.017)$ and inversely to SHBG (rho $=-0.326, p=0.049$ ). Accordingly, $\mathrm{fT}_{4}$ remained inversely related to $\mathrm{CH}(\mathrm{rho}=-0.372, p=0.025)$ and directly to SHBG (rho $=0.443, p=0.007$ ). These results confirm that $\mathrm{CH}$ and SHBG are the most significant tissue effectors of THs action.

Sixty patients were hypercholesterolemic (30 in the study group and 30 in the control group) at baseline, considering the proposed cutoff of $\mathrm{CH}>200 \mathrm{mg} / \mathrm{dL}$. Considering only patients with high $\mathrm{CH}$ serum levels, peripheral tissue markers did not change among visits and between groups.

\section{Multivariate Analyses}

Stepwise multivariate linear analyses were performed considering $\mathrm{TSH}, \mathrm{fT}_{3}$, and $\mathrm{fT}_{4}$ as dependent variables and anthropometrical parameters as independent. No significant models were generated in any group.

\section{DISCUSSION}

Although the beneficial effects of probiotics were demonstrated in several physiopathological conditions, their impact on thyroid function in humans was not evaluated so far. Here, we found that the intake of a probiotic mixture does not alter directly $\mathrm{LT}_{4}$ therapy compensation in patients with primary hypothyroidism on substitutive treatment. Moreover, the probiotics-induced modification of intestinal bacteria seems to be not able to influence $\mathrm{LT}_{4}$ absorption when probiotics are administered at least $2 \mathrm{~h}$ after $\mathrm{LT}_{4}$ intake, since no hormonal serum variation was observed. While serum levels of $\mathrm{TSH}, \mathrm{fT}_{3}$, and $\mathrm{fT}_{4}$ reflect drug absorption, the tissue markers analyzed in this study express THs action at the peripheral level. As a confirmation, no change after probiotics administration was observed. The lack of variation in both circulating hormone levels and THs tissue effect is consistent with the absence of differences in the therapeutic needs between groups and among visits. Nevertheless, a significant difference considering $\mathrm{LT}_{4}$ adjustments required in the two groups was found. Interestingly, controls needed significantly higher $\mathrm{LT}_{4}$ dose adjustments in comparison with cases, even if no changes in the mean $\mathrm{LT}_{4}$ daily dose occurred. We speculate that concomitant probiotics intake could increase the stability in thyroid function compensation. Thus, gut microbiota modification could allow an increased $\mathrm{LT}_{4}$ bioavailability, drawing from the THs intestinal reservoir through enterohepatic recycle. Indeed, the iodothyronines deconjugation is mediated by bacterial enzymes sulfatases and $\beta$-glucuronidases and the VSL $\# 3^{\circledR}$ action on gut microbiota could
TABLE 4 | Peripheral tissue markers of thyroid hormones.

\begin{tabular}{|c|c|c|c|c|}
\hline & $\begin{array}{c}\text { Reference } \\
\text { range }\end{array}$ & $\begin{array}{l}\text { Study } \\
\text { group }\end{array}$ & $\begin{array}{l}\text { Control } \\
\text { group }\end{array}$ & $p$ Value \\
\hline $\mathrm{CH}(\mathrm{mg} / \mathrm{dL})$ & $<200$ & & & \\
\hline Baseline & & $219 \pm 30$ & $222 \pm 37$ & 0.626 \\
\hline Visit 1 (treatment phase) & & $226 \pm 40$ & $224 \pm 39$ & 0.780 \\
\hline Visit 2 (treatment phase) & & $213 \pm 31$ & $214 \pm 48$ & 0.898 \\
\hline Visit 3 (follow-up phase) & & $217 \pm 39$ & $219 \pm 40$ & 0.743 \\
\hline Visit 4 (follow-up phase) & & $220 \pm 27$ & $225 \pm 45$ & 0.582 \\
\hline$p$ value & - & 0.496 & 0.853 & - \\
\hline CK (U/L) & $10-171$ & & & \\
\hline Baseline & & $93 \pm 50$ & $116 \pm 10$ & 0.658 \\
\hline Visit 1 (treatment phase) & & $77 \pm 40$ & $98 \pm 77$ & 0.240 \\
\hline Visit 2 (treatment phase) & & $77 \pm 38$ & $103 \pm 75$ & 0.085 \\
\hline Visit 3 (follow-up phase) & & $115 \pm 137$ & $107 \pm 106$ & 0.759 \\
\hline Visit 4 (follow-up phase) & & $81 \pm 40$ & $97 \pm 86$ & 0.864 \\
\hline$p$ value & - & 0.636 & 0.840 & - \\
\hline Myoglobin (ng/mL) & $15-106$ & & & \\
\hline Baseline & & $24 \pm 11$ & $25 \pm 11$ & 0.616 \\
\hline Visit 1 (treatment phase) & & $21 \pm 8$ & $23 \pm 15$ & 0.599 \\
\hline Visit 2 (treatment phase) & & $21 \pm 6$ & $23 \pm 8$ & 0.165 \\
\hline Visit 3 (follow-up phase) & & $23 \pm 13$ & $24 \pm 10$ & 0.368 \\
\hline Visit 4 (follow-up phase) & & $23 \pm 7$ & $24 \pm 9$ & 0.729 \\
\hline$P$ value & - & 0.569 & 0.545 & - \\
\hline Ferritin (ng/mL) & $25-400$ & & & \\
\hline Baseline & & $51 \pm 61$ & $44 \pm 27$ & 0.102 \\
\hline Visit 1 (treatment phase) & & $47 \pm 53$ & $43 \pm 31$ & 0.201 \\
\hline Visit 2 (treatment phase) & & $41 \pm 43$ & $47 \pm 37$ & 0.078 \\
\hline Visit 3 (follow-up phase) & & $40 \pm 47$ & $41 \pm 31$ & 0.222 \\
\hline Visit 4 (follow-up phase) & & $41 \pm 41$ & $41 \pm 27$ & 0.202 \\
\hline$P$ value & - & 0.992 & 0.881 & - \\
\hline Lipoprotein(a) (mg/dL) & $1-30$ & & & \\
\hline Baseline & & $21 \pm 18$ & $22 \pm 28$ & 0.516 \\
\hline Visit 1 (treatment phase) & & $21 \pm 21$ & $20 \pm 25$ & 0.406 \\
\hline Visit 2 (treatment phase) & & $19 \pm 18$ & $20 \pm 25$ & 0.547 \\
\hline Visit 3 (follow-up phase) & & $19 \pm 19$ & $17 \pm 19$ & 0.537 \\
\hline Visit 4 (follow-up phase) & & $22 \pm 19$ & $19 \pm 25$ & 0.238 \\
\hline$p$ value & - & 0.967 & 0.980 & - \\
\hline Osteocalcin (ng/mL) & $4.6-65.4$ & & & \\
\hline Baseline & & $16.0 \pm 5.6$ & $16.2 \pm 5.2$ & 0.832 \\
\hline Visit 1 (treatment phase) & & $15.4 \pm 5.8$ & $14.4 \pm 6.5$ & 0.475 \\
\hline Visit 2 (treatment phase) & & $15.1 \pm 5.7$ & $14.2 \pm 7.1$ & 0.557 \\
\hline Visit 3 (follow-up phase) & & $14.7 \pm 6.5$ & $14.7 \pm 5.2$ & 0.990 \\
\hline Visit 4 (follow-up phase) & & $14.4 \pm 6.0$ & $14.7 \pm 6.2$ & 0.879 \\
\hline$p$ value & - & 0.826 & 0.598 & - \\
\hline ACE (U/L) & $8-52$ & & & \\
\hline Baseline & & $35 \pm 13$ & $33 \pm 15$ & 0.551 \\
\hline Visit 1 (treatment phase) & & $30 \pm 11$ & $31 \pm 15$ & 0.755 \\
\hline Visit 2 (treatment phase) & & $31 \pm 12$ & $29 \pm 15$ & 0.495 \\
\hline Visit 3 (follow-up phase) & & $32 \pm 13$ & $33 \pm 21$ & 0.820 \\
\hline Visit 4 (follow-up phase) & & $31 \pm 12$ & $32 \pm 15$ & 0.668 \\
\hline$p$ value & - & 0.361 & 0.751 & - \\
\hline SHBG (nmol/L) & $\begin{array}{c}\text { Female } \\
\text { 19.8-155.2 } \\
\text { Male } \\
13.5-71.4\end{array}$ & & & \\
\hline Baseline & & $78.9 \pm 57.2$ & $71.3 \pm 41.3$ & 0.981 \\
\hline Visit 1 (treatment phase) & & $70.5 \pm 45.8$ & $69.4 \pm 41.4$ & 0.992 \\
\hline Visit 2 (treatment phase) & & $74.3 \pm 52.7$ & $72.04 \pm 42.2$ & 0.915 \\
\hline Visit 3 (follow-up phase) & & $72.62 \pm 55.7$ & $72.0 \pm 40.0$ & 0.534 \\
\hline Visit 4 (follow-up phase) & & $78.5 \pm 55.0$ & $71.3 \pm 37.9$ & 0.806 \\
\hline$p$ value & - & 0.951 & 0.994 & - \\
\hline
\end{tabular}

Data are expressed as mean $\pm S D$. $p$ value is considered significant when $<0.05$. $A C E$, angiotensin-converting enzyme; $\mathrm{CH}$, total cholesterol; $\mathrm{CK}$, creatine kinase; SHBG, sex hormone-binding globulin. 
influence the availability of these enzymes. However, in physiological conditions, enterohepatic recycle contributes minimally to circulating THs levels, since sulfated iodothyronines undergo rapid degradation by type 1 deiodinase (17) and deglucuronidation processes seem less important in humans than in animal models (17). This could be the reason of the lack of significant hormonal alterations in this population. However, it is not possible to exclude the presence of a "lessebo effect." This is described as a negative patients' expectation, related to the possibility of not receiving the "active" treatment (42). For this reason, control group patients were possibly less motivated to respect $\mathrm{LT}_{4}$ administration rules while probiotics-treated patients could have a higher motivation.

Regression analyses confirm the known correlations among THs and BMI. Considering peripheral tissue markers of THs, both $\mathrm{TSH}$ and $\mathrm{fT}_{4}$ are related with $\mathrm{CH}$ and SHBG levels, confirming that these markers are sensible to THs (2). Moreover, the $\mathrm{fT}_{3} / \mathrm{fT}_{4}$ ratio showed a direct correlation to $\mathrm{TSH}$ in the control group at each visit, according to physiological feedback mechanism. However, this relationship was lost in the study group after 1 month of probiotic treatment. Thus, probiotics should influence the deiodinases activity, temporarily reducing the feedback. This effect could be explained considering the known anti-inflammatory property of VSL $\# 3^{\circledR}$, through the decrease in circulating pro-inflammatory cytokines (43). Thus, considering that deiodinases expression and activity can be modulated by cytokines (44-48), probiotics could interfere with THs deiodination. This result reinforces the hypothesis that VSL\# $3^{\circledR}$ is able to influence THs metabolism, although a final and significant difference in hormonal levels is not detected. Possibly, a longer treatment might be able to highlight these changes.

Even if VSL\# $3^{\circledR}$ is one of the most highly concentrated probiotics largely used in clinical trials, it does not contain strains expressing $\beta$-glucuronidases and sulfatases, which could directly increase the enterohepatic recycle of iodothyronines. However, contrasting data are available regarding Lactobacilli and Bifidobacteria effects on intestinal $\beta$-glucuronidase activity $(29,49)$. Thus, the VSL\# $3^{\circledR}$ modulation effect on microbiota by stimulating bacteria growth expressing $\beta$-glucuronidases and sulfatases may be only a speculation.

The main limit of this study is represented by the lack of placebo in the control group. It could limit the strength of our results, constituting a sort of "volunteer bias." Accordingly, the dropout rate is higher in the control than in the study group (six vs. three patients), although not significant. Secondly, the difficulty to evaluate probiotics treatment compliance is another notable limit. The sachets counting expresses an estimation of therapeutic compliance, but differences in microbiota composition and enzymatic activity before and after probiotics ingestion were not evaluated. Moreover, the compliance should be measured considering dietary assessment, which was not recorded in our trial. In the literature, several beneficial effects of VSL $\# 3^{\circledR}$ were demonstrated, even if no precise evidence about the minimum probiotics concentration required to influence microbiota is available, representing a limit in all trials using probiotics. Furthermore, despite 2 months treatment period seems to be appropriate to modify gut microbiota $(50,51)$, it is not possible to confirm the exact time-interval needed to obtain a significant change in microbiota composition. Thus, further trials using higher probiotics concentration for longer time should be considered. Finally, in this setting, the accuracy of the TH assay methods remains a crucial point. Commonly used immunoassays could present discrepancies in TH measurement compared to the gold standard, liquid chromatography-tandem mass spectrometry (LC-MSMS), mainly due to pharmacological interferences or pathological conditions able to modify serum transport proteins (52). Nevertheless, the use of LC-MSMS is not currently routinely available in clinical practice and our study population does not present the common conditions that may undermine the immunoassay reliability.

In conclusion, this is the first randomized controlled trial evaluating possible interactions among probiotics, $\mathrm{LT}_{4}$ therapy, and pituitary-thyroid axis. Even if these results show no significant differences in hormonal parameters between groups and among visits, a possible probiotics interaction with THs homeostasis is proposed.

These data generate the hypothesis of a "stabilization" of $\mathrm{LT}_{4}$ treatment after probiotics ingestion, suggested by the reduced dose adjustments needed in the treatment group, as well as the need of a dose reduction observed only in subjects assuming probiotics. In particular, VSL\# $3^{\circledR}$ seems to be able to prevent hormonal fluctuations, perhaps modulating THs enterohepatic recycle and justifying the absence of differences in serum hormonal levels. The effect, however, is limited and no major clinical consequences can be proven at this stage.

The possible probiotics role as " $\mathrm{LT}_{4}$ therapy stabilizers" could be an endearing research starting point for both endocrinologists and investigators concerned with probiotics, in order to clarify the interaction between intestinal environment and endocrine system. This association was not evaluated so far and further studies should explore the relationship between gut microbiota and THs, considering other probiotic strains or longer treatment.

\section{ETHICS STATEMENT}

The Institutional Review Board of Modena (Comitato Etico di Modena) approved the study (code 184/13, approved on 12th November 2013). All procedures performed in studies involving human participants were in accordance with the ethical standards of the institutional and/or national research committee and with the 1964 Helsinki declaration and its later amendments or comparable ethical standards. Written informed consent was obtained from all individual participants included in the study.

\section{AUTHOR CONTRIBUTIONS}

GS collected samples, analyzed the data, and wrote the manuscript. GB conceived the study and wrote the manuscript. SV and UC collected clinical and biochemical data. LR, MS, EB, ST, MV, and TT performed laboratory assays. VR contributed writing the manuscript. MS conceived the study and contributed writing the manuscript. DS conceived the study, analyzed the data, and wrote the manuscript. All authors edited the manuscript or revised it critically for important intellectual content and approved the final draft. 


\section{FUNDING}

DS and GB were recipients of the "SIE Award 2013" of the Italian Society of Endocrinology for the conduction of this study.

\section{REFERENCES}

1. De Groot LJ, Chrousos G, Dungan K, Feingold KR, Grossman A, Hershman JM, et al., editors. SourceEndotext. South Dartmouth, MA: MDText.com, Inc (2014).

2. Jonklaas J, Bianco AC, Bauer AJ, Burman KD, Cappola AR, Celi FS, et al. Guidelines for the treatment of hypothyroidism: prepared by the American thyroid association task force on thyroid hormone replacement. Thyroid (2014) 24(12):1670-751. doi:10.1089/thy.2014.0028

3. Benvenga S, Bartolone L, Pappalardo MA, Russo A, Lapa D, Giorgianni G, et al. Altered intestinal absorption of L-thyroxine caused by coffee. Thyroid (2008) 18(3):293-301. doi:10.1089/thy.2007.0222

4. Ianiro G, Mangiola F, Di Rienzo TA, Bibbo S, Franceschi F, Greco AV, et al. Levothyroxine absorption in health and disease, and new therapeutic perspectives. Eur Rev Med Pharmacol Sci (2014) 18(4):451-6.

5. Lilja JJ, Laitinen K, Neuvonen PJ. Effects of grapefruit juice on the absorption of levothyroxine. Br J Clin Pharmacol (2005) 60(3):337-41. doi:10.1111/j.13652125.2005.02433.x

6. Campbell NR, Hasinoff BB, Stalts H, Rao B, Wong NC. Ferrous sulfate reduces thyroxine efficacy in patients with hypothyroidism. Ann Intern Med (1992) 117(12):1010-3. doi:10.7326/0003-4819-117-12-1010

7. Liwanpo L, Hershman JM. Conditions and drugs interfering with thyroxine absorption. Best Pract Res Clin Endocrinol Metab (2009) 23(6):781-92. doi:10.1016/j.beem.2009.06.006

8. Mersebach H, Rasmussen AK, Kirkegaard L, Feldt-Rasmussen U. Intestinal adsorption of levothyroxine by antacids and laxatives: case stories and in vitro experiments. Pharmacol Toxicol (1999) 84(3):107-9. doi:10.1111/j.1600-0773. 1999.tb00883.x

9. Sachmechi I, Reich DM, Aninyei M, Wibowo F, Gupta G, Kim PJ. Effect of proton pump inhibitors on serum thyroid-stimulating hormone level in euthyroid patients treated with levothyroxine for hypothyroidism. Endocr Pract (2007) 13(4):345-9. doi:10.4158/EP.13.4.345

10. Sherman SI, Tielens ET, Ladenson PW. Sucralfate causes malabsorption of L-thyroxine. Am J Med (1994) 96(6):531-5. doi:10.1016/0002-9343(94)90093-0

11. Singh N, Weisler SL, Hershman JM. The acute effect of calcium carbonate on the intestinal absorption of levothyroxine. Thyroid (2001) 11(10):967-71. doi:10.1089/105072501753211046

12. Siraj ES, Gupta MK, Reddy SS. Raloxifene causing malabsorption of levothyroxine. Arch Intern Med (2003) 163(11):1367-70. doi:10.1001/archinte. 163.11.1367

13. Zamfirescu I, Carlson HE. Absorption of levothyroxine when coadministered with various calcium formulations. Thyroid (2011) 21(5):483-6. doi:10.1089/ thy.2010.0296

14. Centanni M, Gargano L, Canettieri G, Viceconti N, Franchi A, Delle Fave G, et al. Thyroxine in goiter, Helicobacter pylori infection, and chronic gastritis. N Engl J Med (2006) 354(17):1787-95. doi:10.1056/NEJMoa043903

15. Munoz-Torres M, Varsavsky M, Alonso G. Lactose intolerance revealed by severe resistance to treatment with levothyroxine. Thyroid (2006) 16(11): 1171-3. doi:10.1089/thy.2006.16.1171

16. Kuiper GG, Kester MH, Peeters RP, Visser TJ. Biochemical mechanisms of thyroid hormone deiodination. Thyroid (2005) 15(8):787-98. doi:10.1089/ thy.2005.15.787

17. Visser TJ, Peeters RP. Metabolism of thyroid hormone. In: De Groot LJ, BeckPeccoz P, Chrousos G, Dungan K, Grossman A, Hershman JM, et al., editors. Endotext. South Dartmouth, MA: MDText.com, Inc. (2000).

18. Nieuwdorp M, Gilijamse PW, Pai N, Kaplan LM. Role of the microbiome in energy regulation and metabolism. Gastroenterology (2014) 146(6):1525-33. doi:10.1053/j.gastro.2014.02.008

19. Hill C, Guarner F, Reid G, Gibson GR, Merenstein DJ, Pot B, et al. Expert consensus document. The International Scientific Association for probiotics and prebiotics consensus statement on the scope and appropriate use of

\section{SUPPLEMENTARY MATERIAL}

The Supplementary Material for this article can be found online at http://www.frontiersin.org/article/10.3389/fendo.2017.00316/ full\#supplementary-material.

the term probiotic. Nat Rev Gastroenterol Hepatol (2014) 11(8):506-14. doi:10.1038/nrgastro.2014.66

20. Butel MJ. Probiotics, gut microbiota and health. Med Mal Infect (2014) 44(1):1-8. doi:10.1016/j.medmal.2013.10.002

21. Ng SC, Hart AL, Kamm MA, Stagg AJ, Knight SC. Mechanisms of action of probiotics: recent advances. Inflamm Bowel Dis (2009) 15(2):300-10. doi:10.1002/ibd.20602

22. Dwivedi M, Kumar P, Laddha NC, Kemp EH. Induction of regulatory T cells: a role for probiotics and prebiotics to suppress autoimmunity. Autoimmun Rev (2016) 15(4):379-92. doi:10.1016/j.autrev.2016.01.002

23. Vieira AT, Teixeira MM, Martins FS. The role of probiotics and prebiotics in inducing gut immunity. Front Immunol (2013) 4:445. doi:10.3389/fimmu. 2013.00445

24. Dimidi E, Christodoulides S, Fragkos KC, Scott SM, Whelan K. The effect of probiotics on functional constipation in adults: a systematic review and meta-analysis of randomized controlled trials. Am J Clin Nutr (2014) 100(4):1075-84. doi:10.3945/ajcn.114.089151

25. Goldenberg JZ, Ma SS, Saxton JD, Martzen MR, Vandvik PO, Thorlund K, et al. Probiotics for the prevention of Clostridium difficile-associated diarrhea in adults and children. Cochrane Database Syst Rev (2013) 31(5):CD006095.

26. Issa I, Moucari R. Probiotics for antibiotic-associated diarrhea: do we have a verdict? World J Gastroenterol (2014) 20(47):17788-95. doi:10.3748/wjg. v20.i47.17788

27. Khoder G, Al-Menhali AA, Al-Yassir F, Karam SM. Potential role of probiotics in the management of gastric ulcer. Exp Ther Med (2016) 12(1):3-17. doi:10.3892/etm.2016.3293

28. Marchesi JR, Adams DH, Fava F, Hermes GD, Hirschfield GM, Hold G, et al. The gut microbiota and host health: a new clinical frontier. Gut (2016) 65(2):330-9. doi:10.1136/gutjnl-2015-309990

29. Uccello M, Malaguarnera G, Basile F, D’Agata V, Malaguarnera M, Bertino G, et al. Potential role of probiotics on colorectal cancer prevention. BMC Surg (2012) 12(Suppl 1):S35. doi:10.1186/1471-2482-12-S1-S35

30. Davar R, Nokhostin F, Eftekhar M, Sekhavat L, Bashiri Zadeh M, Shamsi F Comparing the recurrence of vulvovaginal candidiasis in patients undergoing prophylactic treatment with probiotic and placebo during the 6 months. Probiotics Antimicrob Proteins (2016) 8(3):130-3. doi:10.1007/ s12602-016-9218-x

31. Griffin C. Probiotics in obstetrics and gynaecology. Aust N Z J Obstet Gynaecol (2015) 55(3):201-9. doi:10.1111/ajo.12303

32. Baquerizo Nole KL, Yim E, Keri JE. Probiotics and prebiotics in dermatology. J Am Acad Dermatol (2014) 71(4):814-21. doi:10.1016/j.jaad.2014.04.050

33. Delzenne NM, Cani PD, Everard A, Neyrinck AM, Bindels LB. Gut microorganisms as promising targets for the management of type 2 diabetes. Diabetologia (2015) 58(10):2206-17. doi:10.1007/s00125-015-3712-7

34. Ferolla SM, Armiliato GN, Couto CA, Ferrari TC. Probiotics as a complementary therapeutic approach in nonalcoholic fatty liver disease. World J Hepatol (2015) 7(3):559-65. doi:10.4254/wjh.v7.i3.559

35. Hur KY, Lee MS. Gut microbiota and metabolic disorders. Diabetes Metab $J$ (2015) 39(3):198-203. doi:10.4093/dmj.2015.39.3.198

36. Sun J, Buys NJ. Glucose- and glycaemic factor-lowering effects of probiotics on diabetes: a meta-analysis of randomised placebo-controlled trials. Br J Nutr (2016) 115(7):1167-77. doi:10.1017/S0007114516000076

37. Yadav H, Lee JH, Lloyd J, Walter P, Rane SG. Beneficial metabolic effects of a probiotic via butyrate-induced GLP-1 hormone secretion. J Biol Chem (2013) 288(35):25088-97. doi:10.1074/jbc.M113.452516

38. Gibson GR, Roberfroid MB. Dietary modulation of the human colonic microbiota: introducing the concept of prebiotics. J Nutr (1995) 125(6): 1401-12.

39. Stojancevic M, Bojic G, Salami HA, Mikov M. The influence of intestinal tract and probiotics on the fate of orally administered drugs. Curr Issues Mol Biol (2014) 16:55-68. 
40. Garber JR, Cobin RH, Gharib H, Hennessey JV, Klein I, Mechanick JI, et al. Clinical practice guidelines for hypothyroidism in adults: cosponsored by the American Association of Clinical Endocrinologists and the American Thyroid Association. Endocr Pract (2012) 18(6):988-1028. doi:10.4158/ EP12280.GL

41. Singh N, Singh PN, Hershman JM. Effect of calcium carbonate on the absorption of levothyroxine. JAMA (2000) 283(21):2822-5. doi:10.1001/jama. 283.21.2822

42. Mestre TA, Shah P, Marras C, Tomlinson G, Lang AE. Another face of placebo: the lessebo effect in Parkinson disease: meta-analyses. Neurology (2014) 82(16):1402-9. doi:10.1212/WNL.0000000000000340

43. Rajkumar H, Mahmood N, Kumar M, Varikuti SR, Challa HR, Myakala SP. Effect of probiotic (VSL\#3) and omega-3 on lipid profile, insulin sensitivity, inflammatory markers, and gut colonization in overweight adults: a randomized, controlled trial. Mediators Inflamm (2014) 2014:348959. doi:10.1155/2014/348959

44. Hosoi Y, Murakami M, Mizuma H, Ogiwara T, Imamura M, Mori M. Expression and regulation of type II iodothyronine deiodinase in cultured human skeletal muscle cells. J Clin Endocrinol Metab (1999) 84(9):3293-300. doi:10.1210/jcem.84.9.5969

45. Huang SA, Mulcahey MA, Crescenzi A, Chung M, Kim BW, Barnes C, et al. Transforming growth factor-beta promotes inactivation of extracellular thyroid hormones via transcriptional stimulation of type 3 iodothyronine deiodinase. Mol Endocrinol (2005) 19(12):3126-36. doi:10.1210/me.2005-0173

46. Kwakkel J, Wiersinga WM, Boelen A. Differential involvement of nuclear factor-kappaB and activator protein-1 pathways in the interleukin-1betamediated decrease of deiodinase type 1 and thyroid hormone receptor betal mRNA. J Endocrinol (2006) 189(1):37-44. doi:10.1677/joe.1.06354

47. Molnar I, Balazs C, Szegedi G, Sipka S. Inhibition of type 2,5'-deiodinase by tumor necrosis factor alpha, interleukin-6 and interferon gamma in human thyroid tissue. Immunol Lett (2002) 80(1):3-7. doi:10.1016/S01652478(01)00301-7
48. Pang XP, Hershman JM, Mirell CJ, Pekary AE. Impairment of hypothalamic-pituitary-thyroid function in rats treated with human recombinant tumor necrosis factor-alpha (cachectin). Endocrinology (1989) 125(1):76-84. doi:10.1210/endo-125-1-76

49. Marteau P, Pochart P, Flourie B, Pellier P, Santos L, Desjeux JF, et al. Effect of chronic ingestion of a fermented dairy product containing Lactobacillus acidophilus and Bifidobacterium bifidum on metabolic activities of the colonic flora in humans. Am J Clin Nutr (1990) 52(4):685-8.

50. Jafarnejad S, Saremi S, Jafarnejad F, Arab A. Effects of a multispecies probiotic mixture on glycemic control and inflammatory status in women with gestational diabetes: a randomized controlled clinical trial. J Nutr Metab (2016) 2016:5190846. doi:10.1155/2016/5190846

51. Ki Cha B, Mun Jung S, Hwan Choi C, Song ID, Woong Lee H, Joon Kim H, et al. The effect of a multispecies probiotic mixture on the symptoms and fecal microbiota in diarrhea-dominant irritable bowel syndrome: a randomized, double-blind, placebo-controlled trial. J Clin Gastroenterol (2012) 46(3):220-7. doi:10.1097/MCG.0b013e31823712b1

52. Welsh KJ, Stolze BR, Yu X, Podsiadlo TR, Kim LS, Soldin SJ. Assessment of thyroid function in intensive care unit patients by liquid chromatography tandem mass spectrometry methods. Clin Biochem (2017) 50(6):318-22. doi:10.1016/j.clinbiochem.2016.11.022

Conflict of Interest Statement: All authors declare that there is no conflict of interest that could be perceived as prejudicing the impartiality of the research reported.

Copyright (C) 2017 Spaggiari, Brigante, De Vincentis, Cattini, Roli, De Santis, Baraldi, Tagliavini, Varani, Trenti, Rochira, Simoni and Santi. This is an open-access article distributed under the terms of the Creative Commons Attribution License (CC BY). The use, distribution or reproduction in other forums is permitted, provided the original author(s) or licensor are credited and that the original publication in this journal is cited, in accordance with accepted academic practice. No use, distribution or reproduction is permitted which does not comply with these terms. 